\title{
Qualidade tecnológica e sensorial de bolos elaborados com soro de leite
}

\author{
Technological and sensory quality of cakes produced with milk whey
}

\author{
Elessandra da Rosa ZAVAREZE ${ }^{1}$, Kessiane Silva MORAES ${ }^{2 *}$, Myriam de Las Mercedes SALAS-MELLADO ${ }^{3}$
}

\section{Resumo}

O presente estudo teve como objetivo utilizar soro de leite in natura concentrado e desidratado na elaboração de bolos e avaliar a influência deste na composição química e nas características tecnológicas e sensoriais do produto. Os resultados foram avaliados estatisticamente por análise de variância (ANOVA), as médias comparadas pelo teste de Tukey $(\mathrm{p} \leq 0,05)$ e os resultados do teste sensorial de ordenação foram avaliados estatisticamente mediante tabela de Friedman. Os bolos com adição de soro apresentaram aumento no teor proteico e no teor de cinzas quando comparados ao bolo padrão. As notas das características tecnológicas dos bolos com soro in natura foram superiores às notas dos bolos com soro concentrado e desidratado. No entanto, na avaliação sensorial, segundo teste de ordenação, os bolos com adição de soro concentrado e desidratado apresentaram preferência por parte dos julgadores em relação ao bolo contendo soro in natura.

Palavras-chave: proteína; teste de preferência; volume específico.

\begin{abstract}
The objective of this work was to make cakes with the addition of liquid, concentrated and dry milk whey to analyze the influence of this ingredient on the chemical composition, and on the technological and sensorial characteristics of cakes. Results were evaluated with variance analysis, the average compared by Tukey's test $(\mathrm{p} \leq 0.05)$ and results of sensorial preference test-rankings were evaluated with the Friedman method. The cakes with the addition of whey presented an increase in protein and ash content when compared with standard cakes. The technological characteristics score of cakes made with liquid whey was higher than the score of cakes made with the addition of concentrated and dry whey. However in the sensorial evaluation through preference test-ranking, cakes with the addition of dry and concentrated whey were preferred by the panelists compared to the cakes with added liquid whey.

Keywords: preference test; protein; specific volume.
\end{abstract}

\section{Introdução}

As mudanças no processamento e a crescente exigência do consumidor por alimentos que apresentem, além da alta qualidade sensorial e nutricional, benefícios associados à saúde, fazem surgir a necessidade de novos ingredientes que possam atender a estas exigências do mercado (IDRIS et al., 1996; MOSCATTO; PRUDÊNCIO-FERREIRA; HAULY, 2004). Pesquisas estão sendo desenvolvidas com a finalidade de encontrar opções para uma melhor utilização do soro do leite, diminuindo assim os problemas com poluição que o descarte provoca no ambiente, devido ao alto teor de matéria orgânica e à alta demanda biológica de oxigênio necessária para a degradação da lactose (NEVES, 2001).

O desenvolvimento de mercados utilizando o soro de leite em pó e frações do soro como ingredientes nos gêneros alimentícios para consumo humano e animal, transformou o então subproduto, em produto valioso para a indústria de laticínios. Ingredientes lácteos à base de soro podem substituir, com eficiência e baixo custo, os sólidos do leite e dar origem a fórmulas alternativas para diversos alimentos (MEILGAARD; CIVILLE; CARR, 1999).
O soro de leite in natura contém aproximadamente 93,6\% de água e $6,4 \%$ de sólidos e o soro desidratado contém em torno de $12 \%$ de proteínas, $3 \%$ de gordura, $10 \%$ de minerais e $75 \%$ de lactose (WONG; CAMIRANT; PAVLATH, 1996). Devido ao elevado teor de água, ao redor de $93 \%$ e reduzido teor de proteína de 0,6 a $0,9 \%$, o uso de soro in natura em produtos alimentícios convencionais tem sido bastante limitado, principalmente pelo custo de secagem (BORGES et al., 2001). As proteínas do soro de leite, além de suas excelentes propriedades nutritivas e fisiológicas, apresentam propriedades fisico-químicas e funcionais muito apreciadas como ingredientes alimentícios (CHATTERTON et al., 2006; VEITH; REYNOLDS, 2004), também utilizadas em diferentes aplicações em tecnologia de alimentos (PÉREZ; WARGON; PILOSOF, 2006; ROMAN; SGARBIERI, 2007; TOSI et al., 2007).

Entre os produtos de panificação, o bolo vem adquirindo crescente importância no que se refere ao consumo e comercialização no Brasil. O desenvolvimento tecnológico possibilitou mudanças nas indústrias transformando a produção de pequena para grande escala (MOSCATTO; PRUDÊNCIO-

\footnotetext{
Recebido para publicação em 11/2/2008

Aceito para publicação em 3/1/2009 (003222)

${ }^{1}$ Ciência e Tecnologia Agroindustrial, Universidade Federal de Pelotas - UFPel, CP 354, CEP 96010-900, Pelotas - RS, Brasil

${ }^{2}$ Engenharia e Ciência de Alimentos, Universidade Federal do Rio Grande - FURG, CP 474, CEP 96201-900, Rio Grande - RS, Brasil,

E-mail:kessi_moraes@hotmail.com

${ }^{3}$ Escola de Química e Alimentos, Universidade Federal do Rio Grande - FURG, CP 474, CEP 96201-900, Rio Grande, RS, Brasil

${ }^{*}$ A quem a correspondência deve ser enviada
} 
FERREIRA; HAULY, 2004). Trata-se de produto obtido pela mistura, homogeneização e cozimento conveniente de massa preparada com farinhas, fermentadas ou não e outras substâncias alimentícias (como, por exemplo, leite, ovos e gordura) (BORGES et al., 2006). O enriquecimento desses produtos com soro de leite confere uma série de vantagens, uma vez que pode melhorar a textura, realçar o sabor e a cor, melhorar a estabilidade e a capacidade emulsificante, além de melhorar o valor nutritivo, visto que as proteínas do soro de leite são de excelente qualidade, não sendo deficientes em nenhum aminoácido e, quando não desnaturadas, as proteínas do soro de leite são altamente solúveis, boas formadoras de espuma e de emulsões (KINSELLA, 1976; SGARBIERI; PACHECO, 1999). Sendo assim, a aplicação de soro de leite em produtos de panificação visa enriquecê-los com proteínas de excelente valor nutricional e baixo custo em relação ao leite.

Desta forma, o presente trabalho teve como objetivo utilizar soro de leite in natura, desidratado e concentrado como ingrediente na formulação de bolo e avaliar a influência deste ingrediente nas características tecnológicas e sensoriais do produto.

\section{Material e métodos}

\subsection{Material}

O soro de leite desidratado e o soro de leite in natura previamente pasteurizado, obtidos pelo processo de fabricação de queijo prato, foram fornecidos pela Indústria de Laticínios Danby Cosulati, localizada no município de Pelotas, RS. Para a obtenção dos bolos, foi usada farinha de trigo especial para bolo obtida na indústria Moinhos do Sul, localizada no município de Rio Grande, RS. Os demais ingredientes, açúcar, gordura vegetal hidrogenada $(\mathrm{GVH})$, ovos, água e fermento químico foram adquiridos no comércio local de Rio Grande, RS.

\subsection{Obtenção do soro concentrado}

O soro de leite in natura com concentração inicial de 7 B Brix foi concentrado em evaporador descontínuo a vácuo,

Tabela 1. Formulação do bolo padrão (A), do bolo contendo soro in natura (B), do bolo contendo soro desidratado (C) e do bolo contendo soro concentrado (D).

\begin{tabular}{lcccc}
\hline \multirow{2}{*}{ Ingredientes $(\mathrm{g})$} & \multicolumn{4}{c}{ Formulações } \\
\cline { 2 - 5 } & $\mathrm{A}$ & $\mathrm{B}$ & $\mathrm{C}$ & $\mathrm{D}$ \\
\hline Farinha de trigo & 300 & 300 & 300 & 300 \\
Açúcar & 180 & 180 & 180 & 180 \\
Ovos & 150 & 150 & 150 & 150 \\
Água & 150 & 15 & 150 & 50 \\
GVH & 120 & 120 & 120 & 120 \\
Fermento químico & 15 & 15 & 15 & 15 \\
Soro in natura* & - & 135 & - & - \\
Soro desidratado* $^{*}$ & - & - & 17 & - \\
Soro concentrado $^{*}$ & - & - & - & 100 \\
\hline
\end{tabular}

${ }^{\star}$ A quantidade de soro de leite adicionado fornece $2,4 \mathrm{~g}$ de proteína para cada formulação. a temperatura de $53{ }^{\circ} \mathrm{C}$ até atingir $14{ }^{\circ}$ Brix, medido com refratômetro a cada 30 minutos, durante 3 horas e 30 minutos. $\mathrm{O}$ soro de leite concentrado foi acondicionado em recipientes plásticos e congelado a $-18^{\circ} \mathrm{C}$ por não mais que duas semanas até sua utilização, o descongelamento foi realizado durante uma noite em temperaturas de 6 a $10^{\circ} \mathrm{C}$. A Figura 1 apresenta o fluxograma de obtenção do soro de leite concentrado.

\subsection{Formulação dos bolos}

Foram elaborados bolos contendo soro de leite in natura, desidratado e concentrado em diferentes proporções nas formulações com o intuito de fornecer a mesma quantidade de proteínas aos produtos. Os bolos foram elaborados conforme as formulações apresentadas na Tabela 1.

Os bolos foram elaborados segundo Neitzel (2006), em que todos os ingredientes, exceto o fermento químico em pó, foram homogeneizados em batedeira planetária (modelo BPA, Arno) por três minutos. Somente então foi adicionado o fermento químico, o qual foi misturado manualmente. Porções de 120 $\mathrm{g}$ de massa de bolo foram distribuídas em fôrmas de alumínio $(15,5 \times 7,5 \times 4,5 \mathrm{~cm})$ previamente untadas com óleo de soja e forradas com papel manteiga, levadas ao forno elétrico (modelo Diplomata 09.01.09, Fischer) pré-aquecido por 15 minutos e assadas durante 45 minutos a $185^{\circ} \mathrm{C}$. O forno foi desligado e os bolos retirados após 10 minutos. A avaliação das características tecnológicas e sensoriais foi realizada após o resfriamento mínimo de três horas.

\subsection{Avaliação da composição química}

O soro de leite in natura, desidratado e concentrado foi caracterizado pelo teor proteico através do método de Kjeldahl $(\% \mathrm{~N} \times 6,25)$. Os bolos tiveram sua composição proximal avaliada pelo conteúdo de cinzas (mufla $550-600{ }^{\circ} \mathrm{C}$ ) e umidade (estufa $105^{\circ} \mathrm{C}$ ) determinadas por método gravimétrico, conteúdo de lipídios determinado pelo método de Soxhlet e proteínas pelo método de Kjeldahl $(\% \mathrm{~N} \times 6,25)$ de acordo com a metodologia oficial da AOAC (1995). Os carboidratos foram calculados pela diferença dos demais componentes.

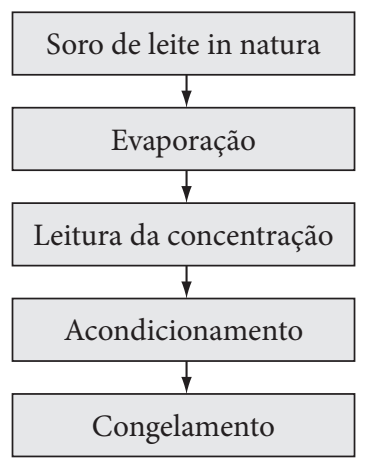

Figura 1. Fluxograma de obtenção de soro de leite concentrado. 


\subsection{Avaliação das características tecnológicas}

$\mathrm{O}$ volume específico $\left(\mathrm{mL} \cdot \mathrm{g}^{-1}\right)$ dos bolos foi obtido pela razão entre o volume aparente $(\mathrm{mL})$ e a massa do bolo após o forneamento (g). O volume aparente foi determinado em equipamento apropriado, dotado de recipiente de volume conhecido e contendo sementes de painço, o volume ocupado por cada bolo neste recipiente foi medido através do deslocamento das sementes para uma proveta graduada (PIZZINATO; CAMPAGNOLLI, 1993). Os atributos de qualidade tecnológica dos bolos foram avaliados segundo AACC (1995). As notas máximas para cada atributo estão apresentadas na Tabela 2.

Para avaliar os atributos de qualidade tecnológica de bolos, uma equipe constituída por quatro indivíduos com experiência em panificação foi treinada para reconhecimento dos atributos e das escalas de avaliação numérica de cada atributo (Tabela 2). Para o treinamento dos julgadores foram utilizadas amostras de bolo padrão.

\subsection{Avaliação sensorial}

A análise sensorial dos bolos adicionados de soro de leite in natura, desidratado e concentrado foi realizada mediante o uso do teste de ordenação (LAWLESS; HEYMANN, 1999) com 50 julgadores não treinados que receberam as quatro amostras simultaneamente em pratos brancos codificados com algarismos de três dígitos e em ordem casualizada, e um copo com água à temperatura ambiente para proceder à avaliação, utilizando a ficha apresentada na Figura 2. Solicitou-se que as amostras fossem ordenadas quanto à preferência em ordem decrescente, ou seja, da preferida para a preterida, sendo atribuído o valor um para amostra preferida e o valor quatro para amostra preterida (ABNT, 1994). O teste foi conduzido em cabines individuais iluminadas com lâmpadas fluorescentes (luz do dia). Os julgadores, de ambos os sexos, todos consumidores de bolos, possuíam entre 20 e 40 anos, foram escolhidos de modo aleatório, sem conhecimento sobre a composição das amostras.

\subsection{Análise estatística}

Os resultados foram avaliados mediante a análise de variância (ANOVA) e as médias comparadas entre si através

Tabela 2. Atributos de qualidade tecnológica de bolos.

\begin{tabular}{lc}
\hline \multicolumn{1}{c}{ Atributos } & Nota máxima \\
\hline Uniformidade das células & 10 \\
Tamanho das células & 10 \\
Espessura das paredes das células & 10 \\
Granulosidade & 16 \\
Umidade & 10 \\
Esfarelamento & 14 \\
Maciez & 10 \\
Cor do miolo & 10 \\
Sabor & 10 \\
Total & 100 \\
\hline
\end{tabular}

do teste de Tukey ao nível de 5\% de significância. Os resultados do teste de ordenação foram avaliados estatisticamente mediante teste não paramétrico de Friedman ao nível de 5\% de significância (MEILGAARD; CIVILLE; CARR, 1999). Todas as análises foram realizadas em triplicata.

\section{Resultados e discussão}

\subsection{Avaliação da composição química}

Verificou-se através do conteúdo proteico mostrado na Tabela 3 que o soro in natura apresentou o menor teor proteico, havendo aumento deste componente após a concentração do soro e aumento consideravelmente maior das proteínas no soro desidratado, o que era esperado devido à concentração dos nutrientes por efeito da operação de secagem.

Devido às diferenças no conteúdo proteico foi necessário adicionar quantidades diferentes de soro na formulação para atingir o mesmo nível de proteínas. Adicionou-se o máximo possível de soro in natura que, por ser o mais diluído, limitou a quantidade máxima de proteína a ser adicionada $(2,4 \mathrm{~g})$.

A Tabela 4 apresenta a composição proximal dos bolos padrão e dos bolos contendo soro de leite.

Na Tabela 4 pode-se observar a composição proximal do bolo elaborados sem a adição de soro (padrão) e com a adição de diferentes tipos de soro de leite. Os bolos elaborados com soro foram enriquecidos com a mesma quantidade de proteína, diferenciando-se apenas o tipo de soro aplicado. A quantidade de proteína adicionada aos produtos foi calculada levando-se em consideração o teor de proteína no soro de leite in natura, o qual apresentou o menor conteúdo proteico quando comparado ao soro de leite concentrado e soro de leite desidratado. O

Nome:_ Idade:_ Data:_______
Avalie cada uma das amostras, da esquerda para a direita, e as
ordene da mais preferida para a menos preferida.
Código da amostra:
Mais preferida
Comentários:

Figura 2. Ficha de avaliação utilizada no teste de ordenação.

Tabela 3. Teor de proteínas do soro de leite in natura, desidratado e concentrado.

\begin{tabular}{lc}
\hline \multicolumn{1}{c}{ Produto $^{*}$} & Proteínas $(\%)$ \\
\hline Soro in natura & $1,7 \pm 0,20^{\mathrm{c}}$ \\
Soro desidratado & $13,4 \pm 0,35^{\mathrm{a}}$ \\
Soro concentrado & $2,5 \pm 0,30^{\mathrm{b}}$ \\
\hline${ }^{*}$ Resultados são médias de três determinações \pm desvio padrão. Letras diferentes na \\
mesma coluna diferem significativamente pelo teste de Tukey (p $\leq 0,05)$.
\end{tabular}


aumento de proteína foi calculado considerando-se o conteúdo de proteína do bolo padrão em base seca. O bolo elaborado com soro in natura apresentou aumento de $11,5 \%$ de proteínas, o bolo com adição de soro concentrado apresentou aumento de 10,3\% de proteínas e o bolo adicionado de soro desidratado apresentou aumento de $10,9 \%$ de proteínas quando comparado ao bolo padrão. Sendo assim, o aumento no conteúdo proteico dos bolos com adição de soro de leite foi semelhante, o que era esperado, com base nos cálculos realizados na formulação dos produtos.

\subsection{Avaliação das características tecnológicas}

A Tabela 5 apresenta as características tecnológicas dos bolos avaliados segundo os atributos da AACC (1995).

Com base na Tabela 5, pode-se observar que as notas das características tecnológicas dos bolos com soro in natura foram superiores às notas dos bolos com soro concentrado e desidratado, inclusive superiores às notas do bolo padrão. Isto pode ser devido à composição e ao grau de desnaturação das proteínas do soro influenciar a sua funcionalidade.

Fatores inerentes a uma aplicação alimentar podem afetar as propriedades funcionais do soro, incluindo a concentração e a desnaturação das proteínas, o pH, o ambiente iônico, o tratamento térmico, bem como a presença de lipídios. Em seu estado nativo, as proteínas de soro são altamente solúveis e promovem com perfeição a emulsificação e a formação de espuma em alimentos industrializados, isto pode justificar as maiores notas tecnológicas para os bolos adicionados de soro in natura quando comparados aos bolos elaborados com soro concentrado e soro desidratado.

A Figura 3 apresenta a fotografia dos bolos elaborados com diferentes tipos de soro. Segundo Vitti e Valle (1987), a lactose reage com os grupos amino livres dos aminoácidos (reação de Maillard), promovendo a formação de crosta escura em produtos de panificação.

A Figura 4 mostra os valores de volume específico do bolo padrão, do bolo com soro in natura, do bolo com soro desidratado e do bolo com soro concentrado.

Através da Figura 4, pode-se observar que apenas os bolos adicionados de soro concentrado apresentaram aumento no volume específico (bolos mais leves), diferindo significativamente $(\mathrm{p} \leq 0,05)$ quando comparados aos bolos elaborados com soro in natura e desidratado. Acredita-se que os bolos elaborados com soro concentrado apresentaram maior volume específico devido

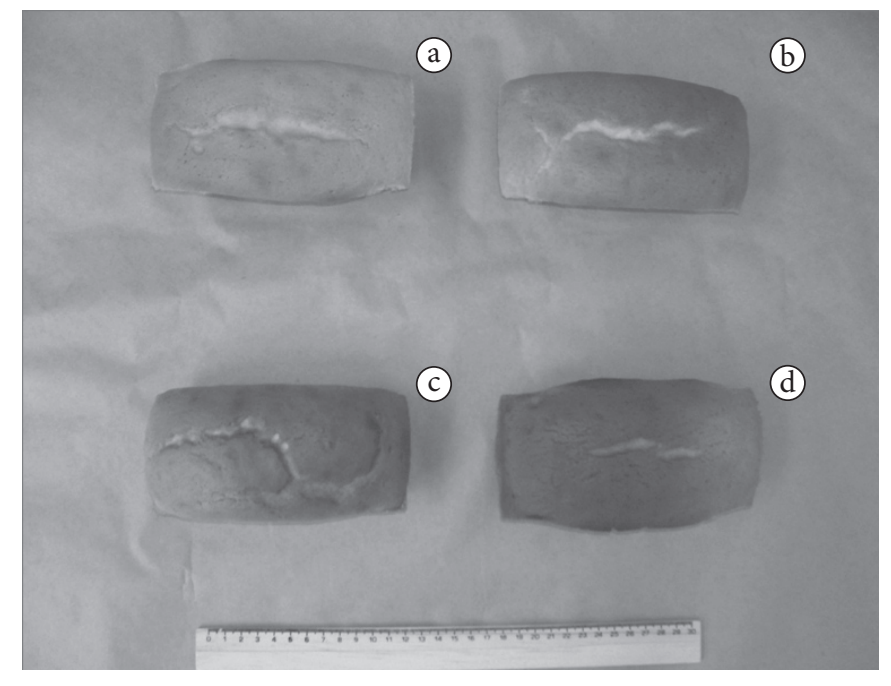

Figura 3. Bolo padrão (a), bolo contendo soro de leite in natura (b), bolo contendo soro desidratado (c) e bolo contendo soro concentrado (d).

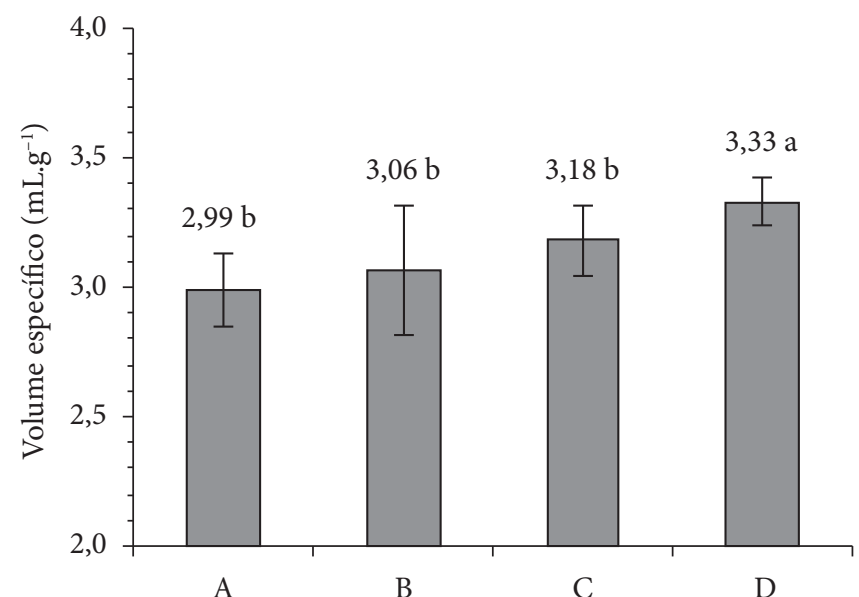

Figura 4. Volume específico do bolo padrão (A), do bolo contendo soro de leite in natura (B), do bolo contendo soro desidratado (C) e do bolo contendo soro concentrado (D). ${ }^{\star}$ Valores seguidos da mesma letra não diferem entre si ao nível de $5 \%$ de significância.

Tabela 4. Composição proximal do bolo padrão (A), do bolo contendo soro in natura (B), do bolo contendo soro desidratado (C) e do bolo contendo soro concentrado (D).

\begin{tabular}{|c|c|c|c|c|c|}
\hline Produto $^{\star}$ & Umidade (\%) & $\begin{array}{c}\text { Cinzas (\%) } \\
\text { b.s }\end{array}$ & $\begin{array}{c}\text { Lipídios (\%) } \\
\text { b.s }\end{array}$ & Carboidratos (\%) b.s & $\begin{array}{c}\text { Proteínas (\%) } \\
\text { b.s }\end{array}$ \\
\hline A & $21,32 \pm 0,10^{c}$ & $1,57 \pm 0,04^{a}$ & $22,09 \pm 0,07^{a b}$ & $66,84 \pm 0,35^{a}$ & $9,50 \pm 0,24^{b}$ \\
\hline B & $22,63 \pm 0,04^{a}$ & $1,63 \pm 0,01^{a}$ & $21,39 \pm 0,08^{b}$ & $66,30 \pm 0,81^{\mathrm{ab}}$ & $10,68 \pm 0,72^{a}$ \\
\hline $\mathrm{C}$ & $22,09 \pm 0,06^{b}$ & $1,66 \pm 0,07$ a & $22,96 \pm 0,64^{a}$ & $64,77 \pm 0,89^{b}$ & $10,61 \pm 0,18^{\mathrm{a}}$ \\
\hline $\mathrm{D}$ & $21,45 \pm 0,06^{\mathrm{c}}$ & $1,64 \pm 0,01^{a}$ & $21,01 \pm 0,61^{\mathrm{b}}$ & $66,78 \pm 0,82^{a}$ & $10,57 \pm 0,20^{\mathrm{a}}$ \\
\hline
\end{tabular}

${ }^{*}$ Resultados são médias de três determinações \pm desvio padrão. Letras diferentes na mesma coluna diferem significativamente pelo teste de Tukey (p $\leq 0,05$ ). 
às propriedades funcionais de suas proteínas, que apresentam grau de desnaturação intermediário em relação ao grau de desnaturação das proteínas do soro desidratado e das nativas do soro in natura. Esta desnaturação proporcionada pela operação de concentração do soro de leite pode ter contribuído para a melhoria do volume específico, visto que o estado parcialmente desnaturado das proteínas favoreceu a capacidade de formação de espuma e de emulsificação do soro de leite, auxiliando na incorporação de ar durante a homogeneização da massa.

A principal exigência para a formação de massa adequada, dependendo do tipo de bolo, é que a mistura tenha quantidade suficiente de proteínas para que durante o forneamento a estrutura proteica formada possa se espalhar sobre os componentes da farinha (MORR; HOFFMANN; BUCHHEIM, 2003). Caso contrário, a fraca estrutura proteica diminui a retenção de gás na massa e favorece a formação de estrutura compacta e de baixo volume. Foegeding, Luck e Davis (2006),

Tabela 5. Atributos avaliados do bolo padrão (A), do bolo contendo soro in natura (B), do bolo contendo soro desidratado (C) e do bolo contendo soro concentrado (D).

\begin{tabular}{lrrrr}
\hline \multicolumn{1}{c}{ Atributos } & $\mathrm{A}$ & $\mathrm{B}$ & $\mathrm{C}$ & $\mathrm{D}$ \\
\hline Uniformidade das células & 6,5 & 7,0 & 8,0 & 5,5 \\
Tamanho das células & 8,0 & 6,8 & 8,0 & 6,0 \\
Espessura das paredes das células & 8,5 & 8,0 & 9,0 & 7,8 \\
Granulosidade & 13,8 & 16,0 & 12,0 & 11,0 \\
Umidade & 9,0 & 9,0 & 8,5 & 8,3 \\
Esfarelamento & 12,3 & 13,8 & 11,3 & 11,3 \\
Maciez & 9,0 & 10,0 & 8,8 & 8,0 \\
Cor do miolo & 8,0 & 8,3 & 7,5 & 7,3 \\
Sabor & 8,8 & 10,0 & 9,8 & 9,8 \\
Total & 83,8 & 88,8 & 82,8 & 74,8 \\
\hline
\end{tabular}

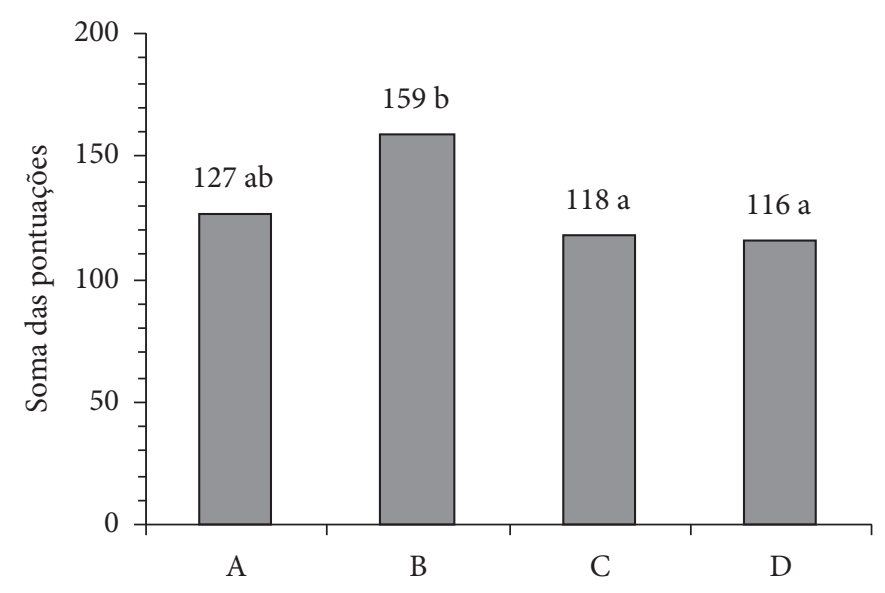

Figura 5. Valores de preferência do teste de ordenação do bolo padrão (A), do bolo contendo soro de leite in natura (B), do bolo contendo soro desidratado (C) e do bolo contendo soro concentrado (D). *Valores seguidos da mesma letra não diferem entre si ao nível de $5 \%$ de significância. constataram que com a elevação da temperatura no forneamento, a desnaturação proteica e a gelatinização do amido determinam o volume do bolo, firmeza ou colapso de sua estrutura. O desenvolvimento simétrico e a qualidade de contorno de massa durante o forneamento constituem características importantes no processamento de produtos de panificação. A forma ou simetria de produtos de panificação deve ser uniforme e bem definida, caso contrário indica manuseio e processamento inadequados (BORGES et al., 2006).

\subsection{Avaliação sensorial}

A Figura 5 apresenta o teste de ordenação usado para avaliar a preferência de quatro amostras de bolos apresentadas a 50 julgadores e os resultados do teste de Friedman, sendo que os valores seguidos da mesma letra não diferem entre si ao nível de 5\% de significância.

Analisando a Figura 5, pode-se observar que os bolos com adição de soro de leite concentrado e desidratado tiveram as menores pontuações no teste de ordenação, ou seja, foram os preferidos pelos julgadores quando comparados ao bolo adicionado de soro in natura, diferindo significativamente $(\mathrm{p} \leq 0,05)$ deste. No entanto, as amostras elaboradas com soro de leite não apresentaram diferença quando comparadas à amostra padrão. Com base nesta avaliação sensorial, a adição da mesma quantidade de proteína dos diferentes tipos de soro de leite em bolos mostrou que os bolos com soro desidratado e concentrado apresentaram maior preferência quando comparados ao bolo com soro in natura, mesmo este tendo apresentado as melhores características tecnológicas.

Sendo assim, levando-se em consideração que o conteúdo proteico é semelhante para todos os bolos, avaliou-se o efeito do soro de leite in natura, concentrado e desidratado nas características tecnológicas e sensoriais dos bolos. A partir da observação dos resultados, o bolo adicionado de soro concentrado apresentou maior volume específico e melhores características sensoriais em relação ao bolo com soro in natura. Desta forma, o soro concentrado apresenta-se como a matériaprima que confere as melhores características aos produtos de panificação, além de apresentar custo de operação inferior ao soro desidratado.

É interessante destacar que em todos os casos a adição de soro manteve ou melhorou as características dos bolos, o que é um resultado promissor, pois, apesar das proteínas do soro serem diferentes das proteínas do trigo, não houve perda na qualidade da estrutura do bolo. No entanto, o bolo com soro concentrado teve algumas características afetadas, tais como cor, uniformidade, tamanho e espessura das células, que podem estar relacionadas a falhas durante o processamento. Por outro lado, o sabor foi uma característica melhorada em todos os casos, e pode ser relacionada às propriedades funcionais das proteínas do soro e à presença de lactose.

\section{Conclusão}

A adição de soro de leite influenciou positivamente a composição química e as características tecnológicas e sensoriais dos bolos. Na avaliação do efeito do soro no produto, verificou-se 
que os três tipos de soro influenciaram de maneira semelhante à qualidade dos bolos, apresentando-se o soro concentrado levemente superior aos soros in natura e desidratado, levando a concluir que os diferentes tipos de soro podem ser utilizados na elaboração de produtos de panificação, dependendo da sua disponibilidade e custo.

\section{Agradecimentos}

Às indústrias Danby Cosulati e Moinhos do Sul pelo fornecimento das matérias-primas.

\section{Referências bibliográficas}

AMERICAN ASSOCIATION OF CEREAL CHEMISTS - AACC. Approved methods of the AACC. 9 ed. Saint Paul, 1995.

ASSOCIAÇÃO BRASILEIRA DE NORMAS TÉCNICAS - ABNT. NBR 13170. Ordenação em análise sensorial de alimentos e bebidas. Rio de Janeiro, 1994. 7 p.

ASSOCIATION OF OFFICIAL ANALYTICAL CHEMISTS - AOAC. Official methods of analysis. 16 ed. USA, 1995. (v. 1-2)

BORGES, P. F. Z. et al. Produção piloto de concentrados de proteínas de leite bovino: composição e valor nutritivo. Brazilian Journal of Food Technology, n. 4, p. 1-8, 2001.

BORGES, J. T. S. et al. Utilização de farinha mista de aveia e trigo na elaboração de bolos. Boletim do CEPPA, v. 24, n. 1, p. 145-162, 2006.

CHATTERTON, D. E. W. et al. Bioactivity of $\beta$-lactoglobulin and a-lactalbumiun: technological implications for processing. International Dairy Journal, v. 16, n. 11, p. 1229-1240, 2006.

FOEGEDING, E. A.; LUCK, P. J.; DAVIS, J. P. Factors determining the physical properties of protein foams. Food Hydrocolloids, v. 20, n. 2-3, p. 284-292, 2006.

IDRIS, N. et al. Performance evaluation of shortenings based on palm oil and butterfat in yellow cake. Fett/Lipid, v. 98, n. 4, p. 144-148, 1996.

KINSELLA, J. E. Functional properties of proteins in foods: a survey. CRC Critical Reviews in Food Science and Nutrition, v. 7, n. 3, p. 219-280, 1976.

LAWLESS, H. T.; HEYMANN, H. Sensory evaluation of food: principles and practices. Maryland: Aspen Publication, 1999.

LUQUET, F. M.; BONJEAN-LINCZOWSKI, Y. Lechey productos lácteos: transformación y tecnologías. Zaragoza: Acribia, 1993. (v. 2).
MEILGAARD, M.; CIVILLE, G. V.; CARR, B. T. Sensory evaluation techniques. 3 ed. Florida: Press, 1999. p. 106-107.

MORR, C. V.; HOFFMANN, W.; BUCHHEIM, W. Use of applied air pressure to improve the baking properties of whey protein isolates in angel food cakes. Lebensmittell-Wissenschaft und-Technologie, v. 36, n. 1, p. 83-90, 2003.

MOSCATTO, J. A.; PRUDÊNCIO-FERREIRA, S. H.; HAULY, M. C. O. Farinha de yacon e inulina como ingredientes na formulação de bolo de chocolate. Ciência e Tecnologia de Alimentos, v. 24, n. 4, p. 634-640, 2004.

NEITZEL, L. H. Influência da formulação no congelamento de massas de bolo e na qualidade do produto final. 2006. $124 \mathrm{p}$. Dissertação (Mestrado em Ciência e Tecnologia Agroindustrial) Universidade Federal de Pelotas - UFPel, Pelotas.

NEVES, B. S. Aproveitamento de subprodutos da indústria de laticínios. In: EMBRAPA. Sustentabilidade da pecuária de leite no Brasil: qualidade e segurança alimentar. Juiz de Fora, 2001. p. 97-108.

PÉREZ, O. E.; WARGON, V.; PILOSOF, A. M. R. Gelation and structural characteristics of incompatible whey proteins/ hydroxypropylmethlcelulose mixtures. Food Hydrocolloids, v. 20, n. 7, p. 966-974, 2006.

PIZZINATO, A.; CAMPAGNOLLI, D. M. F. Avaliação tecnológica de produtos derivados de farinhas de trigo (pão, macarrão, biscoito). Campinas: Instituto de Tecnologia de Alimentos, 1993. 54 p.

ROMAN, J. A.; SGARBIERI, V. C. Caracterização físico-química do isolado protéico de soro de leite e gelatina de origem bovina. Brazilian Journal of Food Technology, v. 10, n. 2, p. 137-143, 2007.

SGARBIERI, V. C.; PACHECO, M. T. B. Alimentos funcionais fisiológicos. Brazilian Journal of Food Technology, v. 2, n. 1-2, p. 7-19, 1999.

TOSI, E. et al. Foaming properties of sweet solutions as modified by thermal treatment. Food Chemistry, n. 100, p. 794-799, 2007.

VEITH, P. D.; REYNOLDS, E. C. Production of a high gel strength whey protein concentrate from cheese whey. Journal of Dairy Science, v. 87, n. 4, p. 831-840, 2004.

VITTI, P.; VALLE, J. L. E. Aproveitamento do soro de leite em panificação e produtos similares. Campinas: Instituto de Tecnologia de Alimentos, 1987. p. 65-71.

WONG, D. W. S.; CAMIRANT, W. M.; PAVLATH, A. E. Structures and functionalities of milk proteins. Critical Reviews in Food Science and Nutrition, v. 36, n. 8, p. 807-844, 1996. 